\title{
Sentinel network for monitoring in vitro susceptibility of Plasmodium falciparum to antimalarial drugs in Colombia: a proof of concept
}

\author{
Samanda L Aponte', Gustavo Díaz ${ }^{1,5}$, Zuleima Pava ${ }^{1,5}$, Diego F Echeverry', \\ Darío Ibarguen ${ }^{3}$, Melissa Rios ${ }^{4}$, Luz M Murcia ${ }^{4}$, Claudia Quelal ${ }^{2}$, Claribel Murillo ${ }^{1 /+}$, \\ Pedro Gil ${ }^{6,7}$, Anders Björkman' ${ }^{6}$, Lyda Osorio'
}

\begin{abstract}
${ }^{1}$ Centro Internacional de Entrenamiento en Investigaciones Médicas, Cali, Colombia ${ }^{2}$ Laboratorio de Control de Vectores, Instituto Departamental de Salud de Nariño, Tumaco, Nariño, Colombia ${ }^{3}$ Laboratorio Departamental Niño Jesús, Secretaría Departamental de Salud de Chocó, Quibdó, Chocó, Colombia ${ }^{4}$ Laboratorio de la Secretaría Departamental de Salud de Amazonas,

Programa de Enfermedades Transmitidas por Vectores, Leticia, Amazonas, Colombia ${ }^{5}$ Escuela de Bacteriología y Laboratorio Clínico, Facultad de Salud, Universidad del Valle, Cali, Colombia ${ }^{6}$ Malaria Research Laboratory, Infectious Diseases Unit, Department of Medicine, Karolinska Institutet, Stockholm, Sweden ${ }^{7}$ Instituto de Biotecnologia e Bioengenharia, Centro de Biomedicina Molecular e Estrutural, Universidade de Algarve, Faro, Portugal
\end{abstract}

\begin{abstract}
Drug resistance is one of the principal obstacles blocking worldwide malaria control. In Colombia, malaria remains a major public health concern and drug-resistant parasites have been reported. In vitro drug susceptibility assays are a useful tool for monitoring the emergence and spread of drug-resistant Plasmodium falciparum. The present study was conducted as a proof of concept for an antimalarial drug resistance surveillance network based on in vitro susceptibility testing in Colombia. Sentinel laboratories were set up in three malaria endemic areas. The enzyme linked immunosorbent assay-histidine rich protein 2 and schizont maturation methods were used to assess the susceptibility of fresh $\mathrm{P}$. falciparum isolates to six antimalarial drugs. This study demonstrates that an antimalarial drug resistance surveillance network based on in vitro methods is feasible in the field with the participation of a research institute, local health institutions and universities. It could also serve as a model for a regional surveillance network. Preliminary susceptibility results showed widespread chloroquine resistance, which was consistent with previous reports for the Pacific region. However, high susceptibility to dihydroartemisinin and lumefantrine compounds, currently used for treatment in the country, was also reported. The implementation process identified critical points and opportunities for the improvement of network sustainability strategies.
\end{abstract}

Key words: Plasmodium falciparum malaria - antimalarial drugs - surveillance

Malaria is an important public health problem worldwide; it causes an estimated 225 million clinical cases and 781,000 deaths per year, predominately in Sub-Saharan Africa (WHO 2010). In Colombia, approximately 79,000 malaria cases are reported annually, with Plasmodium vivax accounting for the most infections (approximately $72 \%$ ) followed by Plasmodium falciparum (27\%) (INS 2010). Eighty percent of Colombian territory is at risk for malaria transmission; moreover, the Pacific region shows the highest incidence for $P$. falciparum infections with 9.3 cases per every 1,000 inhabitants in 2006. In fact, approximately $40 \%$ of all $P$. falciparum cases reported in Colombia annually occur in this region. Other endemic areas are the Urabá bajo-Cauca, Alto-Sinú and the Orinoco-Amazon Basin (INS 2010).

Financial support: anonymous Swiss Foundation, PAHO (057-13144141), COLCIENCIAS (ID 2229-405-20319)

+ Corresponding author: claribel_murillo@cideim.org.co

Received 22 October 2010

Accepted 10 June 2011
Since $P$. falciparum resistance to chloroquine (CQ) was reported in the early 1960s and its subsequent worldwide dissemination, several strategies to monitor antimalarial drug resistance have been proposed. Surveillance is important for the early detection of antimalarial drugs with decreased efficacy and the consequent updating of drug policies (Noedl et al. 2003). Clinical studies have been considered the gold standard for drug resistance surveillance because they take into account host, parasite and drug interactions (OPS-OMS 1998, WHO 2003). However, these studies are costly and logistically complex in countries such as Colombia that have a lowmoderate intensity of transmission with limited access to malaria endemic areas (Ruebush et al. 2003). Clinical efficacy studies of antimalarial drugs in Colombia have shown therapeutic failures of up to $90 \%$ in patients with uncomplicated $P$. falciparum malaria treated with $\mathrm{CQ}$. This evidence was the basis for changing the national antimalarial drug policy in 1999, when CQ was replaced by amodiaquine (AQ) combined with sulfadoxine/pyrimethamine (SP) as the treatment of choice (MS 1999, Osorio et al. 1999, 2002, Blair et al. 2001, 2006, Blair-Trujillo et al. 2002, Castillo et al. 2002). Similarly, therapeutic failures to AQ have reached up to $50 \%$ in the Pacific coast region and therapeutic failures to SP have 
reached up to $87 \%$ in the Amazon Region (Osorio et al. 2007). Since 2006, artemisinin-based combination therapy (ACT) [artemether/lumefantrine (LUM)] has been implemented in Colombia.

The limitations of clinical studies for monitoring antimalarial drug efficacy highlight the need for alternative surveillance methods. Although in vitro methods do not replace in vivo methods, they allow for the detection of intrinsic variations in parasites and help identify when and where to conduct efficacy surveys. Enzyme linked immunosorbent assay (ELISA)-based in vitro drug susceptibility assays have shown accurate results in the field. In particular, the ELISA for histidine rich protein 2 (HRP2) has been described as a reliable method for assessing $P$. falciparum susceptibility to antimalarial drugs in both cultured and fresh isolates. It has shown a high correlation with the microscopy schizont maturation test and radioisotopic tests (Noedl et al. 2002, 2004). The present study was conducted as a proof of feasibility of a surveillance network to monitor antimalarial drug resistance using in vitro susceptibility tests performed directly in endemic areas of Colombia.

\section{PATIENTS, MATERIALS AND METHODS}

Study area - Three sentinel sites were selected taking into account the incidence of P. falciparum malaria, previous reports of therapeutic failures and their strategic location (border area). Two sentinel sites were set up in the Pacific region: Tumaco (state of Nariño) in the South $\left(1^{\circ} 49^{\prime} \mathrm{N} 78^{\circ} 52^{\prime} \mathrm{W}\right)$ and Quibdó (state of Chocó) in the North $\left(5^{\circ} 43^{\prime} \mathrm{N} 76^{\circ} 37^{\prime} \mathrm{W}\right)$. The third site, Leticia (state of Amazonas) ( $\left.4^{\circ} 10^{\prime} \mathrm{S} 69^{\circ} 57^{\prime} \mathrm{W}\right)$, was located in the Amazon Region. Although this state has a relatively low incidence of $P$. falciparum malaria (1.2/1,000 inhabitants in 2009 compared to 6.5 in Chocó and 9.1 in Nariño), they report more therapeutic failures to SP than Pacific region states (Osorio et al. 2007, INS 2010). Leticia is located on the borders with Brazil and Peru, where high levels of therapeutic failures have been reported for both CQ and SP (Ruebush et al. 2003).

Study population - Patients visiting the Ismael Roldan Valencia Hospital or the San Vicente health facility in Quibdó, the Instituto Departamental de Salud de Nariño/Laboratorio de Control de Vectores in Tumaco and the Laboratorio de la Secretaría Departamental de Salud de Amazonas/Programa de Enfermedades Transmitidas por Vectores in Leticia were eligible for the study if they met the inclusion criteria: (i) $\geq$ seven years of age, (ii) $P$. falciparum monoinfection, (iii) parasitaemias between $500-100,000$ trophozoites/ $\mu \mathrm{L}$ and (iv) absence of CQ in the urine (negative Saker-Solomons test) (Saker \& Solomons 1979) (Figure). Patients with clinical evidence of severe malaria were excluded.

Laboratory procedures - In 2006, the in vitro assays were performed by study site technicians; the technicians had previously been trained at the Centro Internacional de Entrenamiento en Investigaciones Médicas (CIDEIM). In 2007, two undergraduate clinical microbiology students were engaged in the project and trained at CIDEIM as part of their internships due to time restric-

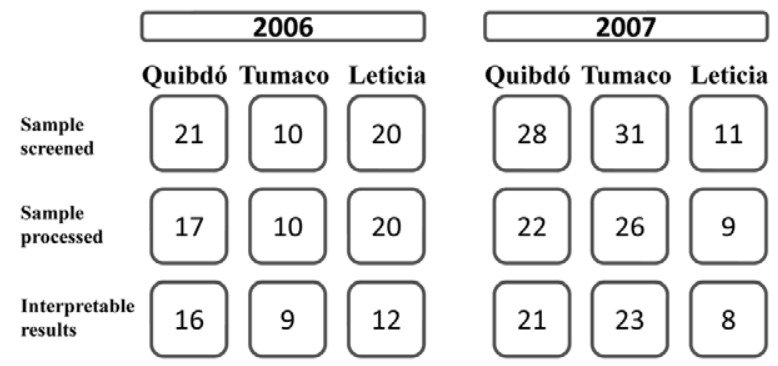

General description of samples included in the study.

tions regarding the availability of personnel in Tumaco and Quibdó. Venous blood samples $(4 \mathrm{~mL})$ were taken in ethylenediamine tetraacetic acid vacutainers (Becton Dickinson) from eligible subjects and processed fresh. Parasitaemia and monoinfection with P. falciparum was confirmed through thick and thin blood smears. Samples with parasitaemias $\geq 15,000$ trophozoites $/ \mu \mathrm{L}$ were adjusted to 5,000 trophozoites $/ \mu \mathrm{L}$ using uninfected $\mathrm{O}^{+}$ erythrocytes for a final concentration of $0.1 \%$ of parasitized red blood cells. Parasite solutions were prepared with $1.5 \%$ haematocrit in Roswell Park Memorial Institute (RPMI) 1640 medium (Sigma-Aldrich) supplemented with $0.5 \%$ albuMAX I ${ }^{\circledR}$ (GIBCO), 25 mM HEPES (Sigma-Aldrich), $25 \mathrm{mM} \mathrm{NaHCO}_{3}$ (pH 7.3) (Sigma-Aldrich), 10 units $/ \mathrm{mL}$ of penicillin and $10 \mu \mathrm{g} / \mathrm{mL}$ of streptomycin (Sigma-Aldrich); next, $200 \mu \mathrm{L}$ of the parasite solutions were added to each well. Positive controls (4-6 per plate) of parasite solutions without drug and negative controls ( 2 per plate) of uninfected blood without drug were included. Samples were incubated at $37^{\circ} \mathrm{C}$ in a standard atmosphere of $5 \% \mathrm{CO}_{2}, 5 \% \mathrm{O}_{2}$ and $90 \% \mathrm{~N}_{2}$ in Quibdó. Samples were incubated under a candle jar atmosphere in Tumaco and Leticia due to the infeasibility of transporting the special gas mixture to these towns. Two identical plates were prepared for each sample. Parasite susceptibility was assessed through the ELISA-HRP2 method in one plate (Noedl et al. 2002) and by a modified schizont maturation method (Noedl et al. 2004) in the other plate. The microscopy schizont method was stopped when the parasites reached at least $10 \%$ schizont maturation in the positive control well. To find the precise moment to stop the experiment, the developing parasites in the positive control wells were examined microscopically beginning at the 16th hour of incubation. If there were not enough schizonts at this time $(<10 \%)$, the plate was incubated again and checked periodically up to the 48th $\mathrm{h}$ of incubation. The time between checks was judged based on the maturation rate. All wells were harvested as Giemsa-stained thick smears according to the World Health Organization protocol guideline (WHO 2001). The percentage of schizonts was determined as the number of schizonts (with 3 or more nuclei) in 200 asexual forms using light microscopy $(1,000 \mathrm{X})$.

For the ELISA-HRP2 assays, the incubation period was $72 \mathrm{~h}$; assays were performed using a commercially available kit (Cellabs) following the manufacturer's instructions. Briefly, plates were frozen and thawed twice 
to release the antigen through parasite lysis. To determine whether the parasites had adapted to culture and the optimal sample dilution prepared antigen dilutions for each sample, we assessed several dilutions $(1: 2.5,1: 3.3,1: 5$ and 1:10) from the positive control and the highest mefloquine (MQ) concentration well, where no parasite growth was expected. The assays were considered valid if the optical density ratio between the positive and basal controls (index growth) was $\geq 1.7$ (Kaddouri et al. 2006).

Antimalarial drug assay - To assay antimalarial drug efficacy, 96-well plates (Becton Dickinson) were precoated at CIDEIM with six antimalarials: CQ diphosphate (Sigma-Aldrich), AQ (Sigma-Aldrich, provided by Walter Reed Army Medical Centre), desethylamodiaquine (MAQ) (Sigma-Aldrich, provided by WHO), MQ hydrochloride (Sigma-Aldrich), dihydroartemisinin (DHA) (Sigma-Aldrich) and LUM (Novartis). Stock solutions of CQ, AQ and MAQ were diluted in distilled water; MQ and DHA were diluted in methanol. LUM was diluted in acid methanol (methanol: acetic acid $99.8 \mathrm{~mL}$ $+0.2 \mathrm{~mL}$ ) (Annerberg et al. 2005). Seven serial dilutions (in RPMI 1640, 1:2) for each drug were pipetted into the wells and the plates were left to dry under sterile conditions. To cover a wide range of parasite drug sensitivities, the drug concentrations ranges were 50-3,200 nanomoles/liter (nM) for CQ, 5-320 nM for AQ and MAQ, 2.5-160 nM for MQ, 0.5-32 nM for LUM and 0.3-16 nM for DHA. Drug plate quality control was performed at CIDEIM using the reference strain W2 (Indochina) and CQ resistance and MQ susceptible strains (provided by Dr Mariano Zalis, Institute of Biophysics Carlos Chagas Filho, Rio de Janeiro University, Brazil). Afterwards, the drug plates were transported refrigerated $\left(4-8^{\circ} \mathrm{C}\right)$ to the sentinel sites and used within two months of preparation (Houzé et al. 2007). LUM was tested only in 2007 and AQ was not tested in Leticia.

Data analysis - The drug concentrations that inhibited $50 \%$ of parasite growth compared to control samples without drug $\left(\mathrm{IC}_{50}\right)$ were calculated using a non-linear regression model with the software Hn-NonLin, which is available from malaria.farch.net. A database was created in Epi Info 6.04d (CDC) and analysed with Stata 9.2 for Windows (StataCorp LP 2006). The $\mathrm{IC}_{50}$ were $\log$-transformed and geometric means were obtained. $\mathrm{IC}_{50}$ among drugs at each sentinel site and between years were compared using a t-test. The WHO schizont maturation method and the ELISA-HRP2 were compared using the Spearman correlation coefficient. A $p$ value of $<$ 0.05 was considered statistically significant.

Quality control - Each year, all microtest slides from three randomly selected samples at each sentinel site were checked at the CIDEIM by an expert microscopist and new $\mathrm{IC}_{50}$ were obtained. The first and second $\mathrm{IC}_{50}$ readings of each drug and sample were compared using the intraclass correlation coefficient. The correlation coefficient in Quibdó was 0.87 (95\% CI, 0.64-0.96) in 2006 and 0.95 (95\% CI, 0.88-0.99) in 2007. In Tumaco, the correlation coefficient was 0.99 (95\% CI, 0.96-0.99) in 2006 and 0.96 (95\% CI, 0.89-0.98) in 2007. In Leticia, the correlation coefficient was 0.64 (95\% CI, -0.04-0.92) in 2006. Therefore, in Leticia, personnel were retrained and all slides from 2006 and 2007 were read again at the CIDEIM; the results read at the CIDEIM were used for analysis. The quality control of ELISA-HRP2 was performed on site during initiation, middle and end monitoring visits. Three samples were re-evaluated in the field and the coefficients of variation between the $\mathrm{IC}_{50}$ values were obtained.

Ethics - Informed, written consent was obtained from subjects aged 18 years or older. For those aged less than 18 years, written consent from a parent or guardian was obtained in addition to patient assent. All subjects received their regular antimalarial treatment regardless of their decision to participate. The study was approved by the Ethical Review Board of the CIDEIM and performed within the framework of ethical policies of Colombia and the Helsinki Declaration and its amendments.

\section{RESULTS}

A total of 121 P. falciparum samples were included in the study; of these, 51 were collected during 2006, while 70 were collected in 2007. Of the total 121 samples, 104 (47 and 57, respectively) were processed (Figure). The geometric mean parasitaemia of samples was 9,020 trophozoites/ $\mu \mathrm{L}$ (range, 1,004-45,000 trophozoites $/ \mu \mathrm{L}$ ). Overall, successful experiments were obtained for $85.5 \%(89 / 104)$ of samples. Sixty-four percent (57/89) with both methodologies (schizont maturation method and ELISA-HRP2) and 36\% (32/89) using just one of those. Some schizont maturation test results were not accurate due to a new parasite cycle that started in less than $18 \mathrm{~h}$ of culture, which invalidates the assay (3 assays). This situation was observed mainly in Quibdó, where some samples grew as fast as $16 \mathrm{~h}$. In contrast, all samples in Leticia had incubation times of $29 \mathrm{~h}$ or more. Similarly, the mean growth index observed in the ELISA-HRP2 assays in Quibdó (6.6; range, 1.5-20) was nearly double that observed in Tumaco (3.6; range, 1.26.6) and Leticia (3.8; range, 3.6-4.2).

In vitro antimalarial drug susceptibilities of fresh $P$. falciparum isolates - We classified parasites as exhibiting low susceptibility (LS) based their $\mathrm{IC}_{50}$ for each drug; parasites with LS had $\mathrm{IC}_{50}$ values of $\geq 100 \mathrm{nM}$ for $\mathrm{CQ}, \geq 30 \mathrm{nM}$ for $\mathrm{AQ}, \geq 60 \mathrm{nM}$ for $\mathrm{MAQ}, \geq 30 \mathrm{nM}$ for MQ and $\geq 10 \mathrm{nM}$ for DHA and LUM. Otherwise, parasites were defined as highly susceptible (HS). Definitions for the HS and LS of parasites were based on the $\mathrm{IC}_{50}$ of the W2 reference strain, which are shown in Table I (Ringwald \& Basco 1999).

LS to CQ $(96.3 \%, 78 / 81)$ and MAQ $(83.7 \%, 67 / 80)$ was observed at all three sentinel sites for both years. In contrast, most samples were HS to AQ (> 85\%). All samples were $\mathrm{HS}$ to DHA $\left(\mathrm{IC}_{50}<10 \mathrm{nM}\right)$ and $\mathrm{LUM}\left(\mathrm{IC}_{50}\right.$ $<10 \mathrm{nM}$ ). Although most samples were HS to MQ, three from Quibdó exhibited LS to MQ. The $\mathrm{IC}_{50}$ obtained during the two years of the study are listed in Table II.

Because different incubation methods were used in Quibdó compared to Tumaco and Leticia, we cannot compare the results between sites. However, the results 
TABLE I

$\mathrm{IC}_{50}$ reference strain W2-Plasmodium falciparum

\begin{tabular}{lccccc}
\hline \multicolumn{5}{c}{$\mathrm{IC}_{50} \mathrm{nM}(95 \% \mathrm{CI})$} \\
\hline $\mathrm{CQ}$ & $\mathrm{AQ}$ & $\mathrm{MAQ}$ & $\mathrm{MQ}$ & $\mathrm{DHA}$ & $\mathrm{LUM}$ \\
\hline $\mathrm{LS}(\geq 100)$ & $\mathrm{LS}(\geq 30)$ & $\mathrm{LS}(\geq 60)$ & $\mathrm{HS}(<30)$ & $\mathrm{HS}(<10)$ & $\mathrm{HS}(<10)$ \\
625.3 & 20.1 & 195.5 & 7.3 & 2.3 & 2.5 \\
$(545.9-704.6)$ & $(11.5-28.6)$ & $(164.8-226.2)$ & $(5.0-9.7)$ & $(1.2-3.4)$ & $(2.5-2.5)$ \\
\hline
\end{tabular}

AQ: amodiaquine; CI: confidence interval; CQ: chloroquine; DHA: dihydroartemisinin; HS: high susceptibility; IC: inhibitory concentration; LS: low susceptibility; LUM: lumefantrine; MAQ: desethylamodiaquine; MQ: mefloquine; nM: nanomoles/liter. Results obtained from two experiments.

from Tumaco and Leticia, which were obtained under the same conditions, showed HS to CQ and MQ in Leticia compared to Tumaco; this difference was stable and statistically significant both in years $(\mathrm{p}<0.001)$ (Table II). The Spearman correlation between the two in vitro susceptibility methods (HRP2 and schizont maturation) was $\mathrm{p}=0.938(\mathrm{p}<0.001)$.

\section{DISCUSSION}

As a drug resistance surveillance tool, one of the advantages of in vitro methodologies is the ability to measure $P$. falciparum susceptibility to several antimalarial drugs simultaneously in the field. This allows for the early detection of changes in the intrinsic parasite response to antimalarial drugs, helping to prioritise, in terms of timing and location, efforts to further evaluate drug efficacy through in vivo surveys.

The sustainability of a surveillance system should be considered prior to implementation. In our case, we identified the need to involve local health authorities as well as local technical staff. In addition, we suggest that short training periods of 30 days and minimal supervision of clinical microbiology undergraduate students (interns at CIDEIM) can strengthen in vitro technical ability at field locations. Human resources are critical for the continuity of the surveillance system. The research centre (in this case CIDEIM) provided technology and scientific transfer to personnel (technicians) from endemic areas and continues to coordinate the logistics and laboratory activities.

This study is limited in its ability to establish geographical variations in drug susceptibility because of differences in the incubation conditions between sites. Parasites were incubated using a gas mixture in Quibdó and candle jar in Tumaco and Leticia. The parasite index growth was 2.5 times higher in Quibdó compared to Tumaco and Leticia, which could be explained by differences in culture conditions. In particular, the candle jar method provides an approximate balance of $1.1-3.3 \%$ of $\mathrm{CO}_{2}$ and $14.5-17.8 \%$ of $\mathrm{O}_{2}$ in contrast to the prepared gas mixture of $5 \% \mathrm{CO}_{2}$ and $5 \% \mathrm{O}_{2}$ (Trager \& Jensen 1976, Scheibel et al. 1979) Previous studies have shown that variations in $\mathrm{O}_{2}$ concentrations can affect parasite growth (Briolant et al. 2007) and that $\mathrm{CO}_{2}$ concentration can affect the $\mathrm{IC}_{50}$ of $\mathrm{pH}$-dependant antimalarials such as CQ (Basco
2007). These facts highlight the importance of keeping standardised procedures for culture conditions and for the quality control of pre-dosed drug plates. For instance, in situations where the gas mixture is unavailable at field sites, an alternative method would be to evaluate reference strains at a central lab using field conditions, which would enable the results to be normalised. The World Wide Antimalarial Resistance Network aims to contribute towards these objectives (Bacon et al. 2007).

Additionally, the inoculum effect is an important concern in the standardisation of in vitro assays. This effect leads to an apparent decrease in drug activity in situations of high parasitaemia, causing a false resistance/ tolerance result (Gluzman et al. 1987). In these experiments, it was demonstrated that parasitaemias of up to $0.5 \%$ were reasonable for in vitro assays without the interference of the inoculum effect. Consistent with these results, Dr Basco stated that: "At parasitaemia, > 1\%, the inoculum effect is observed. The starting parasitaemia must be adjusted to $0.1-1 \%$ for optimal measurement of parasite growth and drug response" (Basco 2007). In our work, the maximum evaluated parasitaemia was up to 14,000 trophozoites $/ \mu \mathrm{L}$, which corresponds to $0.28 \%$ and falls in the range suggested above.

Several events could have affected the in vitro test results. We did not obtain results in 34 ELISA-HRP2 assays because of the following situations: (i) failure to maintain temperature conditions due to power outage (8, all from Tumaco), (ii) HRP2-antigen was not detected with the commercial kit (13 samples, all from Leticia) and (iii) the ratio between positive and basal controls was less than 1.7 (5 samples from Leticia, 6 from Tumaco and 2 from Quibdó).

We suggest that for the implementation of the ELISAHRP2 assay at field sites, the following procedures and guidelines should be adopted. Prior to sample processing with the HRP2 kit, we performed a pretest curve that allowed us to determine the optimal antigen dilution, while also providing evidence as to whether the parasite had been adapted to culture without using an entire plate. We observed that optical densities varied widely between isolates; consequently, the same antigen dilution factors could not necessarily be applied to different samples. This variability in HRP2 detection could be a result of differ- 
TABLE II

Plasmodium falciparum geometric mean $\mathrm{IC}_{50}(\mathrm{nM})$ obtained each year per sentinel site according to the in vitro susceptibility assay used

A. Quibdó

\begin{tabular}{|c|c|c|c|c|c|c|c|}
\hline \multirow[b]{2}{*}{ Year } & \multirow[b]{2}{*}{ Test } & \multicolumn{6}{|c|}{$\mathrm{IC}_{50}(\mathrm{nM})$ of antimalarial drug $(95 \% \mathrm{CI})$} \\
\hline & & CQ (n) & AQ (n) & MAQ (n) & MQ (n) & DHA (n) & LUM (n) \\
\hline \multirow[t]{4}{*}{2006} & 1 & $426.7(15)$ & $23.3(15)$ & $130.1(15)$ & $38.5(15)$ & $0.5(14)$ & ND \\
\hline & & $(291.5-624.6)$ & $(17.6-30.8)$ & $(98-172.6)$ & $(26-57.2)$ & $(0.4-0.8)$ & - \\
\hline & 2 & $412.3(15)$ & $23(15)$ & $106.6(14)$ & $36.2(15)$ & $0.8(15)$ & ND \\
\hline & & $(314.2-541.1)$ & $(17.8-29.6)$ & $(85.3-133.4)$ & $(27.39-47.93)$ & $(0.6-1.1)$ & - \\
\hline \multirow[t]{4}{*}{2007} & 1 & $248.4(18)$ & $14.3(18)$ & $68.3(18)$ & $44.1(18)$ & $1(14)$ & $4.1(4)$ \\
\hline & & $(188.9-326.8)$ & $(11.9-17.3)$ & $(53.6-87.2)$ & $(32.6-59.8)$ & $(0.82-1.39)$ & $(1.3-12.6)$ \\
\hline & 2 & $177.4(17)$ & $12.8(17)$ & 47 (17) & $29.4(17)$ & $1.2(13)$ & $2.6(4)$ \\
\hline & & $(133.8-235.2)$ & $(10.4-15.7)$ & $(36.2-61)$ & $(23-37.7)$ & $(0.9-1.8)$ & $(2.3-3)$ \\
\hline \multicolumn{8}{|c|}{ B. Tumaco } \\
\hline & & \multicolumn{6}{|c|}{$\mathrm{IC}_{50}(\mathrm{nM})$ of antimalarial drug $(95 \% \mathrm{CI})$} \\
\hline Year & Test & CQ (n) & $\mathrm{AQ}(\mathrm{n})$ & MAQ (n) & MQ (n) & DHA (n) & LUM (n) \\
\hline \multirow[t]{3}{*}{2006} & 1 & $319.2(9)$ & $25.1(9)$ & $134.7(9)$ & $17(8)$ & $0.9(1)$ & ND \\
\hline & & $(278.7-365.6)$ & $(19-33.2)$ & $(105.2-172.6)$ & $(9.4-30.7)$ & - & - \\
\hline & 2 & $140.7(1)$ & $17.6(1)$ & $173.4(1)$ & $7.4(1)$ & ND & ND \\
\hline \multirow[t]{4}{*}{2007} & 1 & $341.5(21)$ & $23.1(21)$ & $120.6(20)$ & $24.2(21)$ & $0.8(21)$ & $4.5(5)$ \\
\hline & & $(272.5-428)$ & $(18.6-28.6)$ & (94.4-154.1) & $(17.3-33.9)$ & $(0.6-0.9)$ & $(2.4-8.5)$ \\
\hline & 2 & $213.5(17)$ & $21.3(17)$ & $109.2(16)$ & $22.7(17)$ & $1(17)$ & $4(5)$ \\
\hline & & $(174.4-261.3)$ & $(17.3-26.3)$ & $(86.2-138.3)$ & $(17.7-29.2)$ & $(0.8-1.1)$ & $(1.7-9)$ \\
\hline \multicolumn{8}{|c|}{ C. Leticia } \\
\hline & & \multicolumn{6}{|c|}{$\mathrm{IC}_{50}(\mathrm{nM})$ of antimalarial drug $(95 \% \mathrm{CI})$} \\
\hline Year & Test & CQ (n) & AQ (n) & MAQ (n) & MQ (n) & DHA (n) & LUM (n) \\
\hline \multirow[t]{3}{*}{2006} & 1 & $140.7(1)$ & $17.6(1)$ & $173.4(1)$ & $7.4(1)$ & ND & ND \\
\hline & 2 & $160.5(12)$ & ND & $102.8(12)$ & $9.1(11)$ & ND & ND \\
\hline & & $(123-209.6)$ & - & $(80.3-131.6)$ & $(7-12.2)$ & - & - \\
\hline \multirow[t]{4}{*}{2007} & 1 & $162.2(6)$ & $20.3(2)$ & $119.2(6)$ & $7.1(6)$ & $1.9(2)$ & $<2.5(1)$ \\
\hline & & $(133.7-196.8)$ & $(12.5-33.1)$ & $(85.4-166.2)$ & $(3.8-13.3)$ & $(1.7-2.2)$ & - \\
\hline & 2 & $109.2(3)$ & $17.2(2)$ & $91(3)$ & $7.7(3)$ & $0.6(2)$ & $<2.5(2)$ \\
\hline & & $(42.5-280.4)$ & $(6.3-46.6)$ & $(24.4-339.4)$ & $(1.7-33.1)$ & $(0.4-0.8)$ & - \\
\hline
\end{tabular}

AQ: amodiaquine; CI: confidence interval; CQ: chloroquine; DHA: dihydroartemisinin; IC: inhibitory concentration; LUM: lumefantrine; MAQ: desethylamodiaquine; MQ: mefloquine; n: number of samples tested; ND: not determined; test 1: microscopic evaluation; test 2: enzyme linked immunosorbent assay-histidine rich protein 2.

ences in initial parasitaemia, time of patient infection, genetic variability or the differential expression pattern of the HRP2 protein, factors that all influence the antigenantibody reaction (Baker et al. 2005, Lee et al. 2006). Additionally, 65\% (13/20) of the samples from Leticia that were successfully analysed with the schizont maturation method did not yield results using the ELISA-HRP2 methodology due to undetectable levels of HRP2. These results suggest the presence of genetic polymorphisms in HRP2 or that a proportion of P. falciparum isolates from this region do not produce HRP2 or HRP3 (Uguen et al. 1995, Traore et al. 1997, Gamboa et al. 2010).

The recruitment and compliance of patients was particularly high in Tumaco and Quibdó in 2007, when personnel were dedicated full-time to the in vitro assays. The experience gained in the field with the ELISA-based 
methods will allow for a replacement of subjective and laborious methods such as the schizont maturation assay. Although the ELISA-HRP2 method could be used routinely at field sites in endemic areas, implementation still requires site-specific adjustments that had not been previously described when assessing fresh $P$. falciparum parasites.

A high prevalence $(96.3 \%)$ of parasites with in vitro LS to CQ $\left(\mathrm{IC}_{50}>100 \mathrm{nM}\right)$ was found at all sentinel sites. These results concur with the low efficacy of CQ against P. falciparum throughout Colombia that has been previously reported in therapeutic efficacy studies (Osorio et al. 1999, 2002, Blair et al. 2001, 2006, Blair-Trujillo et al. 2002, Castillo et al. 2002). Despite the fact that CQ was withdrawn for P. falciparum treatment in Colombia as early as 2000, it is still in use for $P$. vivax infections and remains available in the market, possibly enabling it to exert drug selection pressure on P. falciparum strains. Also, more than $80 \%$ of parasites exhibited a markedly reduced sensitivity to MAQ $\left(\mathrm{IC}_{50}>60 \mathrm{nM}\right)$, which is consistent with therapeutic efficacy studies showing that AQ is no longer useful for the treatment of P. falciparum malaria. This is especially the case for Tumaco, where therapeutic failures of up to $50 \%$ have been reported (González et al. 2003).

Our results showed high sensitivity of $P$. falciparum to DHA and LUM at all three sentinel sites, predicting a high efficacy for the ACT approach recently implemented in Colombia. The relatively LS of parasites to $\mathrm{MQ}$ found in Quibdó requires close monitoring due to the potential emergence and spread of resistance to this drug. This finding could be explained by the use of halofantrine, a phenanthrenemethanol-type amino alcohol that has shown cross-resistance with MQ (Cowman et al. 1994), which is available in Quibdó but not at the other two sentinel sites.

In vitro surveillance networks together with molecular markers, clinical trials and pharmacokinetics are useful tools in the documentation of emerging drug resistance (Bacon et al. 2007, Sibley et al. 2008). This study shows that an antimalarial drug resistance surveillance network based on in vitro methods is feasible in Colombia and possibly in other Latin America countries where therapeutic efficacy studies are costly and limited.

\section{ACKNOWLEDGEMENTS}

To the health authorities of Nariño, Chocó and Amazonas, to Harald Noedl, for his helpful advice in establishing the HRP2 assay, to Ligia Pérez, Pilar Pérez, Zulma Bejarano, Luis Quiñonez and Mariela Huertas, malaria diagnostics health facilities personnel, to the participants, for their collaboration, and to $\mathrm{Ru}-$ biela Giraldo, for helping with the sample collection in Quibdó.

\section{REFERENCES}

Annerberg A, Singtoroj T, Tipmanee P, White NJ, Day NP, Lindegårdh N 2005. High throughput assay for the determination of lumefantrine in plasma. $J$ Chromatogr B Analyt Technol Biomed Life Sci 822: 330-333.

Bacon DJ, Jambou R, Fandeur T, Le Bras J, Wongsrichanalai C, Fukuda MM, Ringwald P, Sibley CH, Kyle DE 2007. World Antimalarial Resistance Network (WARN) II: in vitro antimalarial drug susceptibility. Malar J 6: 120.
Baker J, McCarthy J, Gatton M, Kyle DE, Belizario V, Luchavez J, Bell D, Cheng Q 2005. Genetic diversity of Plasmodium falciparum histidine-rich protein 2 (PfHRP2) and its effect on the performance of PfHRP2-based rapid diagnostic tests. $J$ Infect Dis 192: 870-877.

Basco LK 2007. Field application of in vitro assays sensitivity of human malaria parasites antimalarial drugs, WHO, Geneve, $202 \mathrm{pp}$.

Blair S, Carmona-Fonseca J, Piñeros JG, Ríos A, Alvarez T, Alvarez G, Tobón A 2006. Therapeutic efficacy test in malaria falciparum in Antioquia, Colombia. Malar J 5: 14.

Blair S, Lacharme-Lora L, Carmona-Fonseca J, Tobón A 2001. Resistance of Plasmodium falciparum to 3 antimalarials in Turbo (Antioquia, Colombia), 1998. Rev Panam Salud Publica 9: 23-29.

Blair-Trujillo S, Lacharme-Lora L, Carmona-Fonseca J 2002. Resistance of Plasmodium falciparum to antimalarial drugs in Zaragoza (Antioquia, Colombia), 1998. Mem Inst Oswaldo Cruz 97: 401-406.

Briolant S, Parola P, Fusaï T, Madamet-Torrentino M, Baret E, Mosnier J, Delmont JP, Parzy D, Minodier P, Rogier C, Pradines B 2007. Influence of oxygen on asexual blood cycle and susceptibility of Plasmodium falciparum to chloroquine: requirement of a standardized in vitro assay. Malar J 6: 44.

Castillo CM, Osorio LE, Palma GI 2002. Assessment of therapeutic response of Plasmodium vivax and Plasmodium falciparum to chloroquine in a malaria transmission free area in Colombia. Mem Inst Oswaldo Cruz 97: 559-562.

Cowman AF, Galatis D, Thompson JK 1994. Selection for mefloquine resistance in Plasmodium falciparum is linked to amplification of the $p f m d r l$ gene and cross-resistance to halofantrine and quinine. Proc Natl Acad Sci USA 91: 1143-1147.

Gamboa D, Ho MF, Bendezu J, Torres K, Chiodini PL, Barnwell JW, Incardona S, Perkins M, Bell D, McCarthy J, Cheng Q 2010. A large proportion of $P$. falciparum isolates in the Amazon Region of Peru lack $p f h r p 2$ and $p f h r p 3$ : implications for malaria rapid diagnostic tests. PLoS ONE 5: e8091.

Gluzman IY, Schlesinger PH, Krogstad DJ 1987. Inoculum effect with chloroquine and Plasmodium falciparum. Antimicrob Agents Chemother 1: 32-36.

González IJ, Padilla JQ, Giraldo LE, Saravia NG 2003. Efficacy of amodiaquine and sulfadoxine/pyrimethamine in the treatment of malaria not complicated by Plasmodium falciparum in Nariño, Colombia, 1999-2002. Biomedica 23: 38-46.

Houzé S, Munier A, Paoletti X, Kaddouri H, Ringwald P, Le Bras J 2007. Shelf life of predosed plates containing mefloquine, artemisinin, dihydroartemisinin, and artesunate as used for in vitro Plasmodium falciparum susceptibility assessment. J Clin Microbiol 45: 2734-2736.

INS - Instituto Nacional de Salud, Colombia 2010. Informe epidemiológico nacional 2009. Subdirección de vigilancia y control de salud pública. Bogotá. Available from: ins.gov. $\mathrm{co} /$ ?idcategoria $=82972$.

Kaddouri H, Nakache S, Houzé S, Mentré F, Le Bras J 2006. Assessment of the drug susceptibility of Plasmodium falciparum clinical isolates from Africa by using a Plasmodium lactate dehydrogenase immunodetection assay and an inhibitory maximum effect model for precise measurement of the 50-percent inhibitory concentration. Antimicrob Agents Chemother 50: 3343-3349.

Lee N, Baker J, Andrews KT, Gatton ML, Bell D, Cheng Q, McCarthy $\mathrm{J}$ 2006. Effect of sequence variation in Plasmodium falciparum histidine- rich protein 2 on binding of specific monoclonal antibodies: implications for rapid diagnostic tests for malaria. J Clin Microbiol 44: 2773-2778. 
MS - Ministerio de Salud, Colombia 1999. Guía de Atención clínica para el diagnóstico y tratamiento de la malaria. Ministerio de Salud - Dirección General de Promoción y Prevención, Bogotá DC, Colombia. Available from: hospitalraulorejuelabuenoese.gov. co/SOPORTE_MAGNETICO_DE_NORMAS_2009/SUBDIRECCION_CIENTIFICA/Resolucion_412_de_2000/Guia_de_ Atencion_3/Malaria.pdf.

Noedl H, Attlmayr B, Wernsdorfer WH, Kollaritsch H, Miller RS 2004. A histidine-rich protein 2-based malaria drug sensitivity assay for field use. Am J Trop Med Hyg 71: 711-714.

Noedl H, Wernsdorfer WH, Kollaritsch H, Looareesuwan S, Miller RS, Wongsrichanalai C 2003. Malaria drug-susceptibility testing. HRP2-based assays: current data, future perspectives. Wien Klin Wochenschr 115 (Suppl. 3): 23-27.

Noedl H, Wernsdorfer WH, Miller RS, Wongsrichanalai C 2002. Histidine-rich protein II: a novel approach to malaria drug sensitivity testing. Antimicrob Agents Chemother 46: 1658-1664.

OPS-OMS - Organización Panamericana de la Salud, Organización Mundial de la Salud 1998. Evaluación de la eficacia terapéutica de los medicamentos para el tratamiento del paludismo por Plasmodium falciparum sin complicaciones en las Américas. Washington. Available from: paho.org/spanish/HCP/HCT/doc452.pdf.

Osorio LE, Ferro BE, Castillo CM 2002. Effects of chloroquine and sulfadoxine/pyrimethamine on gametocytes in patients with uncomplicated Plasmodium falciparum malaria in Colombia. Mem Inst Oswaldo Cruz 97: 1221-1223.

Osorio LE, Giraldo LE, Grajales LF, Arriaga AL, Andrade AL, Ruebush TK 2nd, Barat LM 1999. Assessment of therapeutic response of Plasmodium falciparum to chloroquine and sulfadoxine-pyrimethamine in an area of low malaria transmission in Colombia. Am J Trop Med Hyg 61: 968-972.

Osorio LE, Pérez LP, González IJ 2007. Assessment of the efficacy of antimalarial drugs in Tarapacá, in the Colombian Amazon Basin. Biomedica 27: 133-140.

Ringwald P, Basco LK 1999. Comparison of in vivo and in vitro tests of resistance in patients treated with chloroquine in Yaoundé, Cameroon. Bull World Health Organ 77: 34-43.
Ruebush TK 2nd, Marquiño W, Zegarra J, Neyra D, Villaroel R, Avila JC, Díaz C, Beltrán E 2003. Practical aspects of in vivo antimalarial drug efficacy testing in the Americas. Am J Trop Med Hyg 68: 391-397.

Saker EG, Solomons ET 1979. A rapid inexpensive presumptive test for phencyclidine and certain others cross-reacting substances. J Anal Toxicol 3: 220-221.

Scheibel LW, Ashton SH, Trager W 1979. Plasmodium falciparum: microaerophilic requirements in human red blood cells. Exp Parasitol 47: 410-418.

Sibley CH, Barnes KI, Watkins WM, Plowe CV 2008. A network to monitor antimalarial drug resistance: a plan for moving forward. Trends Parasitol 24: 43-48.

Trager W, Jensen JB 1976. Human malaria parasites in continuous culture. Science 193: 673-675.

Traore B, Lazaro E, Gay F 1997. A bioassay for evaluating antimalarial activity and for measuring concentration in plasma. Trop Med Int Health 2: 929-933.

Uguen C, Rabodonirina M, De Pina JJ, Vigier JP, Martet G, Maret M, Peyron F 1995. ParaSight-F rapid manual diagnostic test of Plasmodium falciparum infection. Bull World Health Organization 73: 643-649.

WHO - World Health Organization 2001. In vitro micro-test (mark iii) for the assessment of the response of Plasmodium falciparum to chloroquine, mefloquine, quinine, amodiaquine, sulfadoxine/ pyrimethamine and artemisinin. Geneva. Available from: who. int/malaria/publications/atoz/markiii.pdf.

WHO - World Health Organization 2003. Assessment and monitoring of antimalarial drug efficacy for the treatment of uncomplicated falciparum malaria. Geneva. Available from: whqlibdoc.who.int/ hq/2003/WHO_HTM_RBM_2003.50.pdf.

WHO - World Health Organization 2010. World Malaria Report 2009. Geneve. Available from: whqlibdoc.who.int/ publications/2009/9789241563901_eng.PDF. 